\title{
Caregivers satisfaction with care received by paediatric oncology patients admitted at the University Teaching Hospital-Lusaka Zambia
}

\author{
Queen Pule, Esther Mulilo, Lucia Lushinga, Josephine Miti, Patricia Katowa-Mukwato* \\ School of Nursing Sciences, University of Zambia, Lusaka, Zambia
}

Received: October 9, 2017

DOI: $10.5430 /$ jnep.v8n6p22
Accepted: December 12, 2017 Online Published: January 2, 2018

URL: https://doi.org/10.5430/jnep.v8n6p22

\begin{abstract}
Background: Diagnosis of cancer is a traumatic event that does not only affect the diagnosed patients but also their caregivers. Supportive interventions are therefore essential for the caregivers to go through the cancer pathway and attain a sense of satisfaction for both medical and none medical services. Therefore evaluating the extent to which patients and their caregivers are satisfied with health services is clinically relevant as satisfied patients are more likely to comply with treatment, take an active role in their own care, continue using medical care services and stay under the care of a health provider.

Methods: This was a descriptive cross-sectional study that investigated caregiver satisfaction with care received by paediatric oncology patients at the Paediatrics University Teaching Hospital, Lusaka-Zambia. Purposive sampling was used to select study participants and all caregivers who were available in the paediatric oncology ward at the time of data acquisition were selected resulting into a sample size of 50 caregivers. Data was collected using a structured interview schedule.

Results: More than half $26(52 \%)$ of the respondents were knowledgeable about cancer disease, $13(26 \%)$ were partially knowledgeable with only 11 (22\%) were not knowledgeable. Despite high knowledge levels, 19 (38\%) did not know the cancer stage of their child. The majority $30(60 \%)$ of patients had partial access to cancer treatment with only $3(6 \%)$ who reported having full access to treatment. Concerning professional support, majority $47(94 \%)$ received good or very good support from the staff while only $3(6 \%)$ received poor support. When all the factors assumed to influence satisfaction were considered, 18 $(36 \%)$ of the respondents were very satisfied, $19(38 \%)$ were partially satisfied with only $13(26 \%)$ who were not satisfied with care received. Of the five factors which were hypothesized to influence caregiver satisfaction, only professional support had a significant association with caregiver satisfaction with a $p$ value of .004 .

Conclusions: Only professional support had a significant association with caregiver satisfaction against all other factors hypothesized to influence satisfaction, implying that if appropriate profession support is given, caregivers are more likely to get satisfied with care and consequently comply with treatment.
\end{abstract}

Key Words: Caregivers, Satisfaction, Care, Paediatric oncology patient

\section{BACKGROUND}

Globally, about 43 children are diagnosed with cancer every day, 40,000 undergo treatment and 12\% do not survive every year. ${ }^{[1]}$ In Great Britain, researchers predicted that 1 in 500 children will develop some form of cancer by 14 years of age with Leukaemia being the most commonly diagnosed cancer

\footnotetext{
*Correspondence: Patricia Katowa-Mukwato; Email: patriciakatowamukwato@gmail.com; Address: School of Nursing Sciences, University of Zambia, Lusaka, Zambia.
} 
in children. ${ }^{[2]}$ In sub Saharan Africa, It is difficult to measure the incidence of childhood cancer accurately. Cases are often unreported with greater frequency of death from infectious diseases and malnutrition. ${ }^{[3]}$ According to Chintu, ${ }^{[4]}$ Zambia has recorded an increase in the occurrence of total childhood cancers with lymphoma being the commonest reported childhood malignancy followed by retinoblastoma and Kaposi's sarcoma.

With regard to survival, Smith, 2010 asserts that childhood cancer survival rates are high in high income countries (HICs) and have continued to improved dramatically over the past half century. Global studies have revealed that advances in treatment have increased the overall 5 year survival rate while in the 1960 s it was $30 \%$ and is now nearly $80 \% .{ }^{[5]}$ Contrary to the situation in high income settings, childhood cancer survival rate in many countries of Sub Saharan Africa remains low due to late diagnosis and poor access to treatment. ${ }^{[6]}$ Zambia for example, has recorded poor treatment completion rates which are due in part to the logistical challenges faced by families, low educational status, and significant distance from the hospital. ${ }^{[7]}$

Diagnosis of cancer is a traumatic event. ${ }^{[8]}$ It does not only affect the patient but also their caregivers. Therefore, evaluating the extent to which patients and their caregivers are satisfied with health services is clinically relevant as satisfied patients are more likely to comply with treatment, take an active role in their own care, continue using medical care services and stay within a health provider. According to Bowman, ${ }^{[8]}$ supportive interventions are essential for the caregivers to go through the cancer pathway since diagnosis does not only affect the patient but also devastates and traumatizes their caregivers as both patients and caregivers face substantial needs. Davies et al. ${ }^{[9]}$ define a family caregiver as an unpaid family member, friend, or neighbour who provides care to an individual who has an acute or chronic condition and needs assistance to manage a variety of tasks, from bathing, dressing, and taking medications to tube feeding and ventilator care.

Considering that caregivers play an important role in providing social and emotional support for the cancer patients and influence how well patients manage their health, supportive interventions are essential for these caregivers. ${ }^{[10]}$ Studies have reported that knowledge and psychosocial support are the common caregiver needs. Peterson and colleagues, ${ }^{[11]}$ states that low social support as well as care giving burden induced stress and anxiety are common among cancer caregivers. Further literature attests that caregivers experience physical problems such as fatigue, pain, sleep problems and psychological distress. As for the Paediatric Oncology patients, the top five identified needs for both patients and caregivers are social work services, play activities during treatment and insurance to cover medical care. Others are educational activities, and cancer-related medical services. ${ }^{[11]}$

Davies and colleagues, ${ }^{[9]}$ further reported a reduction in burden and distress for caregivers who receive friendly, socially supportive phone calls that provided some respite from care giving, even without in-home caregiver skills training. Furthermore, home visits and enhanced social support also can help reduce caregiver depression. Studies found that family caregivers of patients with advanced cancer reported psychological support and a range of information needs of a practical nature including pain control, weakness and fatigue, home care services, management of depression, management of weight loss and appetite loss. ${ }^{[12]}$

Due to the physical stress, psychological distress at times depression and disruption to identity and family structure that caregivers experience ${ }^{[11,13]}$ it is important to measure their level of satisfaction with care they receive. According to Hannon, ${ }^{[14]}$ satisfaction with care is important for quality assurance in oncology. Satisfaction is defined as the extent of an individual's experience compared with his or her expectations. ${ }^{[15]}$ Evaluating the extent to which patients are satisfied with health services is clinically relevant as satisfied patients are more likely to comply with treatment, take an active role in their own care, continue using medical care services and stay within a health provider. ${ }^{[16]}$

Caregivers seem to desire greater involvement in treatment decisions. ${ }^{[14]}$ Therefore, every clinical system needs to recognize the caregiver's role in patient care and partner with the caregiver as well as the patient to deliver patient and family centred care. Consequently, designing a system that not only supports but fosters caregiver engagement can increase caregiver satisfaction and need fulfilment. ${ }^{[17]}$ Many factors are involved in determining caregivers' satisfaction such as need for attention, support, continuity and communication. According to Sajjadi, ${ }^{[18]}$ caregivers expect good service delivery and more appropriate services in order to promote satisfaction and to improve quality of life. The objective of this study therefore was to investigate factors influencing caregiver satisfaction with care received by paediatric oncology patients at the Paediatrics University Teaching Hospital, Lusaka-Zambia. It was hypothesized that there was no association between the caregivers' satisfaction with care received by paediatric oncology patients and the following factors; knowledge of condition and treatment outcomes, cancer staging of the child, physical dependence of the child, access to oncology treatment modalities and professional support. 


\section{MATERials AND MethodS}

This study utilized a descriptive cross- sectional design. Purposive sampling was used to select study units. All caregivers who were available in the paediatric oncology ward at the time of data acquisition were selected. The sample size was therefore 50 caregivers because the ward has an average of 50 patients per month.

In this study, data was collected using a structured interview schedule. It consisted of questions that obtained information on demographic characteristics, knowledge of condition and treatment outcomes, cancer staging of the child, physical dependence of the child, access to treatment modalities and professional support. An informed consent was obtained from caregivers who agreed to participate in the study, prior to the administration of the interview schedule.

Data were analyzed using SPSS version 20 software computer package. Chi square test was used to test the association between dependent and independent variables. The cut off point for statistical significance was set at $5 \%$. Therefore only $p$ value of less than or equal to .05 was considered to be statistically significant.

\section{RESUlts}

Out of the 50 caregivers interviewed, majority 19 (38\%) where above 42 years of age. There were more females 37 (74.0\%) than males $13(26 \%)$ caregivers with $34(68 \%)$ who were married against $16(32 \%)$ who were not married. Almost all 49 (98\%) were Christians with only $1(2 \%)$ was Buddhist. Majority of the respondents 34 (68\%) came from outside Lusaka the capital city of Zambia while 16 (32\%) were from within Lusaka. Almost two thirds of the respondents $32(64 \%)$ were taking care of their biological child while $18(36 \%)$ were taking care of a relative. With regard to education and employment status, Majority of the respondents $23(46 \%)$ reached secondary school level while very few respondents 5 (10\%) acquired tertiary education. Almost half of the respondents $24(48 \%)$ were self employed while $10(20 \%)$ were formally employed and $16(32 \%)$ were unemployed.

Table 1 shows that $19(38 \%)$ respondents did not know the cancer stage of the patient, however almost two thirds 32 $(64 \%)$ indicated that their patients were able to carry out all activities of daily living, 15(30) were able to carry out some activities while $3(6 \%)$ were unable to carry out any. With regard to knowledge of the condition, more than half 26 (52\%) were knowledgeable about cancer disease, 11 (22\%) were not knowledgeable, while 13 (26\%) were partially knowledgeable. Findings further revealed that majority of the respondents $30(60 \%)$ could only partially access cancer treatment with only $3(6 \%)$ who report having full access to treatment. Concerning the support that the caregivers received, majority $47(94 \%)$ indicated that they either received good or very good support from the staff while only $3(6 \%)$ received poor support. When all the factors assumed to influenced satisfaction were considered, $18(36 \%)$ of the respondents very satisfied, $19(38 \%)$ were partially satisfied with only 13 (26\%) who were not satisfied with care received.

Of the five factors which were hypothesized to influence caregiver satisfaction; level of education, cancers stage of the patient, ability of patient to perform activities of living, access to cancer treatment and professional support, only professional support had a significant association with caregiver satisfaction as shown in table two.

\section{Discussion}

Satisfaction is the fulfilment of one's wishes, expectations, needs or the pleasure derived from this. This study revealed that $19(38 \%)$ of the respondents were partially satisfied with the care received, $18(36 \%)$ were satisfied with care received while $13(26 \%)$ indicated that they were not at all satisfied with care received. This shows that most of the respondents were at least satisfied with care and this could be attributed to the good professional support received and adequate information acquired about cancer condition. ${ }^{[12]}$

In this study, Professional support was the only variable that showed a significant association with Satisfaction with care in a chi-square test performed $\left(\chi^{2}=.004\right)$. We therefore, rejected the null hypothesis which stated that there is no association between the caregiver's satisfaction with care received by Paediatric oncology Patients and Professional support.

Our findings are supporting findings of a study conducted by Nigel and colleagues, ${ }^{[19]}$ in Canada in 2002 on parental satisfaction regarding the consultation of Paediatric patients with cancer as part of the evaluation of a change of the cancer treatment as previously done. The authors concluded that all parents appeared satisfied with the care received.

In another study by Mack and colleagues, ${ }^{[20]}$ to evaluate the quality of care of Paediatric patients with malignant conditions conducted in America. It was established that out of the 144 parents interviewed, $70 \%$ of parents rated the quality of care by their medical oncologists as excellent, $12 \%$ as very good, $10 \%$ as good, $2 \%$ as acceptable, and $5 \%$ as poor quality of care. A greater number of those sampled were satisfied with care received. It could be assumed that in United States of America the standard of care is good and hence the satisfaction with medical services. Similarly, Ringdal, ${ }^{[21]}$ in Norway conducted a study with the aim to assess family 
Satisfaction with End-of-Life Care for Cancer Patients in a with care they had received.

Cluster. The results revealed that caregivers were satisfied

Table 1. Factors hypothesized to influencing caregiver satisfaction with care and level of satisfaction

\begin{tabular}{|c|c|c|}
\hline & Frequency & Percent (\%) \\
\hline \multicolumn{3}{|l|}{ Cancer Stage } \\
\hline Stage 1 & 7 & 14.0 \\
\hline Stage 2 & 7 & 14.0 \\
\hline Stage 3 & 10 & 20.0 \\
\hline Stage 4 & 7 & 14.0 \\
\hline Doesn’t know & 19 & 38.0 \\
\hline Total & 50 & 100.0 \\
\hline \multicolumn{3}{|c|}{ Child's ability to carry out Activities of daily Living } \\
\hline All Activities & 32 & 64.0 \\
\hline Some activities & 15 & 30.0 \\
\hline None & 3 & 6.0 \\
\hline Total & 50 & 100.0 \\
\hline \multicolumn{3}{|l|}{ Level of knowledge } \\
\hline Knowledgeable & 26 & 52.0 \\
\hline Partially knowledgeable & 13 & 26.0 \\
\hline Not knowledgeable & 11 & 22.0 \\
\hline Total & 50 & 100.0 \\
\hline \multicolumn{3}{|l|}{ Access to cancer treatment } \\
\hline Easily Accessible & 3 & 6 \\
\hline Partially Accessible & 30 & 60 \\
\hline Not accessible & 17 & 34 \\
\hline Total & 50 & 100 \\
\hline \multicolumn{3}{|l|}{ Professional Support } \\
\hline Very good support & 10 & 20.0 \\
\hline Good support & 37 & 74.0 \\
\hline Poor support & 3 & 6.0 \\
\hline Total & 50 & 100.0 \\
\hline \multicolumn{3}{|c|}{ Level of Satisfaction with care } \\
\hline Very Satisfied & 18 & 36.0 \\
\hline Partially satisfied & 19 & 38.0 \\
\hline Not satisfied & 13 & 26.0 \\
\hline Total & 50 & 100.0 \\
\hline
\end{tabular}

On the other hand, Sajjadi and colleagues, ${ }^{[18]}$ in Iran assessed quality of life in caregivers of children with cancer and investigated the relationship between the caregivers' quality of services and satisfaction with care in the social work section. Results were that caregivers of children with cancer reported that they go through the cancer pathway and attain a sense of satisfaction for both medical and none medical services.

Other findings are further in line with a study conducted in India, ${ }^{[22]}$ entitled needs of informal Caregiver of Terminally
Ill Cancer patients'. The study reported that most of the caregivers who were in middle age had no prior experience of care giving. The caregivers were however satisfied by the information and medical support provided to them by their treatment team. The unmet needs of the caregivers were homecare, psychological support, and financial help.

Another factor which was thought to influence satisfaction was the cancer stage of the patient. However for this study, a chi-square test showed no significant relationship between 
level of satisfaction with care and cancer staging of the child the rest of the caregivers were able to indicate cancer stage $\left(\chi^{2}=0.769\right)$. Weller ${ }^{[23]}$ describes cancer staging as the sever- of their patients. Regardless of most caregivers being knowlity of an individual's cancer based on the magnitude of the original primary tumour as well as on the extent cancer has spread in the body. From a sample of 50 respondents 19 $(38 \%)$ did not know the cancer staging of their patient, while edgeable on their patients' condition, the majority did not know the cancer stage of their children. This could be due to delayed investigations to confirm diagnosis.

Table 2. Caregiver Satisfaction versus, level of education, cancers stage of the patient, performance of activities of living, access to cancer treatment and professional support

\begin{tabular}{|c|c|c|c|c|c|c|c|c|c|}
\hline & & \multicolumn{8}{|c|}{ Highest Level of Education of the Caregiver } \\
\hline & & \multicolumn{2}{|l|}{ Primary } & \multicolumn{2}{|c|}{ Secondary } & Tertially & Not schooling & Total & $p$-value \\
\hline \multirow{4}{*}{$\begin{array}{l}\text { Level of } \\
\text { Satisfaction } \\
\text { with care }\end{array}$} & Satisfied & $6(12 \%)$ & & $7(1$ & & $3(6 \%)$ & $2(4 \%)$ & $18(36 \%)$ & \multirow{4}{*}{.720} \\
\hline & Partially Satisfied & $6(12 \%)$ & & $8(1$ & & $1(2 \%)$ & $4(8 \%)$ & $19(38 \%)$ & \\
\hline & Not Satisfied & $3(6 \%)$ & \multicolumn{3}{|c|}{$8(16 \%)$} & $1(2 \%)$ & $1(2 \%)$ & $13(26 \%)$ & \\
\hline & Total & $15(30 \%)$ & \multicolumn{3}{|c|}{$23(46 \%)$} & $5(10 \%)$ & $7(14 \%)$ & $50(100 \%)$ & \\
\hline & & \multicolumn{8}{|c|}{ Cancer stage of the patient } \\
\hline & & Stage 1 & Stage & & Stage 3 & Stage 4 & Doesn't know & Total & $p$-value \\
\hline \multirow{6}{*}{$\begin{array}{l}\text { Level of } \\
\text { Satisfaction } \\
\text { with care }\end{array}$} & Satisfied & $4(8 \%)$ & $3(6 \%)$ & & $2(4 \%)$ & $3(6 \%)$ & $6(12 \%)$ & $18(36 \%)$ & \multirow{4}{*}{.769} \\
\hline & Partially Satisfied & $1(2 \%)$ & $2(4 \%)$ & & $4(8 \%)$ & $3(6 \%)$ & $9(18 \%)$ & $19(38 \%)$ & \\
\hline & Not Satisfied & $2(4 \%)$ & $2(4 \%)$ & & $4(8 \%)$ & $1(2 \%)$ & $4(8 \%)$ & $13(26 \%)$ & \\
\hline & Total & $7(14 \%)$ & $7(14 \%$ & & $10(20 \%)$ & $7(14 \%)$ & $19(38 \%)$ & $50(100 \%)$ & \\
\hline & & \multicolumn{8}{|c|}{ Child's Performance of Activities of Daily Living } \\
\hline & & \multicolumn{3}{|c|}{ All of them } & \multicolumn{2}{|c|}{ Some of them } & None & Total & $p$-value \\
\hline \multirow{6}{*}{$\begin{array}{l}\text { Level of } \\
\text { Satisfaction } \\
\text { with care }\end{array}$} & Satisfied & \multicolumn{3}{|l|}{$9(18 \%)$} & \multicolumn{2}{|l|}{$7(14 \%)$} & $2(4 \%)$ & $18(36 \%)$ & \multirow{4}{*}{.486} \\
\hline & Partially Satisfied & \multicolumn{3}{|l|}{$14(28 \%)$} & \multicolumn{2}{|l|}{$4(8 \%)$} & $1(2 \%)$ & 19 (38\%) & \\
\hline & Not Satisfied & \multicolumn{3}{|l|}{$9(18 \%)$} & $4(8 \%)$ & & $0(0 \%)$ & $13(26 \%)$ & \\
\hline & Total & 32 (64\%) & & & 15 (30\%) & & $3(6 \%)$ & $50(100 \%)$ & \\
\hline & & Access to & ancer $t$ & treat & & & & & \\
\hline & & Easily Ac & ssible & & Partially & Accessible & Not Accessible & Total & $p$-value \\
\hline & Satisfied & $2(4 \%)$ & & & $12(24 \%)$ & & $4(8 \%)$ & $18(36 \%)$ & \\
\hline Level of & Partially Satisfied & $0(0 \%)$ & & & $12(24 \%)$ & & 7 (14\%) & 19 (38\%) & 41 \\
\hline Satusraction & Not Satisfied & $1(2 \%)$ & & & $6(12 \%)$ & & $6(12 \%)$ & $13(26 \%)$ & .418 \\
\hline & Total & $3(6 \%)$ & & & $30(60 \%)$ & & 17 (34\%) & 50 (100\%) & \\
\hline & & Caregive & Leve & el of & owledge a & bout the di & ses & & \\
\hline & & Knowled & able & & ally Knov & vledgeable & Not Knowledgeable & Total & $p$-value \\
\hline & Satisfied & $9(18 \%)$ & & & & & $2(4 \%)$ & $18(36 \%)$ & \\
\hline Level of & Partially Satisfied & 9 (18\%) & & & & & 5 (10\%) & $19(38 \%)$ & 210 \\
\hline with care & Not Satisfied & $8(16 \%)$ & & & & & $4(8 \%)$ & $13(26 \%)$ & (1) \\
\hline & Total & 26 (52\%) & & & $6 \%)$ & & $11(22 \%)$ & 50 (100\%) & \\
\hline & & Professio & 1 Supp & port & & & & & \\
\hline & & Very goo & suppor & & Good suI & pport & Poor Support & Total & $p$-value \\
\hline & Satisfied & 7 (14\%) & & & $11(22 \%)$ & & $0(0 \%)$ & $18(36 \%)$ & \\
\hline Level of & Partially Satisfied & $3(6 \%)$ & & & $16(32 \%)$ & & $0(0 \%)$ & 19 (38\%) & \\
\hline $\begin{array}{l}\text { Satisfaction } \\
\text { with care }\end{array}$ & Not Satisfied & $0(0 \%)$ & & & $10(20 \%)$ & & $3(6 \%)$ & 13 (26\%) & .004 \\
\hline & Total & 10 (20\%) & & & 37 (74\%) & & $3(6 \%)$ & 50 (100\%) & \\
\hline
\end{tabular}


With regard to knowledge of the condition as one of the factors that could influence satisfaction, this study revealed that the majority 26 (52\%) of the respondents were knowledgeable about cancer disease, 13 (26\%) were partially knowledgeable while 11 (22\%) were not knowledgeable. For our study, knowledge was measured using knowledge test component of the interview schedule. The knowledge levels were therefore determined using the ability to define cancer, state the signs and symptoms and indicate treatment and common side effects. Therefore those who scored between 7-10 on the knowledge questions were regarded as knowledgeable; those who scored between 4-7 were regarded as partially knowledgeable while those who scored below 4 were regarded as not knowledgeable. The finding that majority of the respondents were knowledgeable, could be attributed to good professional support and long hospital stays which made caregivers understand their children's conditions better and became more knowledgeable about the condition. However, there was no significant statistical relationship between level of satisfaction with care and level of knowledge $\left(\chi^{2}=\right.$ 0.316).

Our study findings on knowledge are in agreement with those of a study conducted by Iconomou ${ }^{[24]}$ in Greece. The objective was to identify the specific informational needs of primary caregivers of cancer patients receiving chemotherapy in a Greek outpatient setting and to assess their preference for cancer-specific booklets, their levels of satisfaction with communication and their psychological status. The main findings were that a significant proportion of the caregivers had elevated needs for information, which were positively associated with a preference for cancer-specific printed material but negatively associated with satisfaction with the doctor's communication of information and affective behaviour. Participants expressed preference for printed material and were satisfied with communication. The results suggest that the Greek cancer caregiver needed more factual information relevant to the patient's condition and that communication of information is critical if caregivers are to be satisfied.

This is also supported by a study conducted by McKenna et al. ${ }^{[25]}$ in UK with the aim to evaluate Parental involvement in paediatric cancer treatment decision. The study investigated parents' information needs and involvement in decision-making processes affecting the care of children diagnosed with cancer. Parents reported that doctors contributed almost twice as much to the decision-making process as they did, but parental satisfaction positively correlated with the amount of information provided when giving informed consent. Information and support tailored to parents' specific needs may therefore enhance satisfaction with clinical decision making and reassure parents about decisions made in

Published by Sciedu Press the long-term interest of their child's health.

Another factor that was assumed to influence satisfaction was accessibility to cancer treatment modalities. The findings of our study revealed that out of a sample of 50 respondents the majority $30(60 \%)$ could partially access treatment as these stayed outside Lusaka where the only cancer diseased hospital in the country was located. A small number $3(6 \%)$ easily accessed treatment. These were coming from within Lusaka, few minutes away from cancer treatment facility while 17 (34\%) responded that cancer treatment was not accessible. This indicated that distance from the hospital had an influence on accessibility to treatment and was likely to affect satisfaction with care. However, a Chi Square test performed to assess the association between access to treatment and caregiver satisfaction revealed that there was no association between level of satisfaction and access to cancer treatment $\left(\chi^{2}=.418, \mathrm{df}=4, p>.05\right)$.

Findings of our study supports are in agreement with those of a study conducted in California by Lavergne and colleagues, ${ }^{[26]}$ highlighted socio-demographic variables such as patients' income as factors which limit access to treatment modalities. Lavergne et al. ${ }^{[26]}$ argued that those families from low income groups had lower rates of consultations and utilization of various treatment modalities in Califonia. Other patient dependent barriers to access included lower education level and lack of support. In addition easy accessibility to the hospital which offers cancer treatment were suggested to motivate caregivers to take their patients for treatment promptly and as scheduled. Similarly, Walker ${ }^{[27]}$ conducted a study in Tanzania about perception of family cancer care givers. Results from the study suggested that caregivers in Tanzania experience challenges in meeting their needs during the care situation. Limited resources made it difficult to afford transportation to and from health centres and to provide food for the family and the patient. Findings of such studies suggest the importance of access to cancer treatment facilities in the promotion of patient and caregiver satisfaction.

Caregiver burden has been reported to affect satisfaction with care. ${ }^{[28]}$ As a means for determining caregivers burden for our study participants, the caregivers were asked on the ability of their patients in carrying out activities of daily living. The findings were that, majority 32 (64\%) indicated that their patients were able to carry out all the activities of daily living. The other $15(30 \%)$ were able to carry some activities of daily living while $3(6 \%)$ were not able to carry out any activities of daily living. Contrary to our assumption, that physical dependability is associated satisfaction with care, our study findings revealed that there was no association 
between Physical dependence of a child (ability to carry out activities of daily living) and satisfaction $\left(\chi^{2}=0.486\right)$.

Our findings are contrary to those a study conducted in Ko$\mathrm{rea}^{[28]}$ entitled burdens, needs and satisfaction of terminal cancer patients and their caregivers. Terminally ill cancer patients and caregivers were interviewed to determine how much burden they experienced and to establish what factors are most important for satisfaction in advanced cancer stage. The study revealed that the burden was great in both terminal cancer patients and their caregivers and was perceived to be more severe by caregivers. The study further indicated that burden was the factor for satisfaction with care in both groups. The caregivers felt more burdened and placed greatest emphasis on discussion about further treatment plans as this influenced satisfaction with care.

\section{Study limitation}

The sample comprised of only 50 purposefully selected respondents from University Teaching Hospital as such the findings cannot be generalized to other settings.

\section{Conclusion}

Out of the five factors which were hypothesized to influence caregiver satisfaction; level of education, cancers stage of the patient, ability of patient to perform activities of living, access to cancer treatment and professional support, our study revealed that only professional support had a significant association with caregiver satisfaction. In literature, there have been varied findings regarding factors that influence caregiver satisfaction with care. Most scholar have agreed that appropriate environmental conditions, emotional support, professional support, factual information related to the patient's condition and need, homecare, and financial help are the major factors that influence satisfaction with care received by paediatric oncology patients while others have found no association between satisfaction and the stated factors. Our study has therefore added on to the discourse while pointing at professional support as having significant influence on caregiver satisfaction. To this effect, we recommend appropriate profession support including provision of information about the condition and treatment modalities, referral to sources of social and financial support, and advocacy to easy access to care. Such support can enable caregivers to realistically go through the cancer pathway and attain a sense of satisfaction for both medical and none medical services.

\section{CONFlicts OF INTEREST Disclosure}

The authors declare no conflict of interest.

\section{REFERENCES}

[1] Gross S. Cure Search for Children's Cancer. 4600 East West Highway, Suite 600, Bethesda. 2015

[2] Cancer Research UK. Cancer Statistics. Angel Building, 407 St John Street, London EC1V4AD. 2015.

[3] Garcia M, Jemal A, Ward E, et al. Global Cancer Facts \& Figures. Atlanta, GA: American Cancer Society. 2007.

[4] Chintu C, Athale UH, Patil PS. Childhood cancers in Zambia before and after, the HIV epidemic. UTH, Lusaka Zambia. 1995. https://doi.org/10.1136/adc.73.2.100

[5] Murphy S, Xu J, Kochanek K. Deaths Final Data for 2010. National Vital Statistics. Nagel K, Eves M, Waterhouse L. et al.The development of an off-therapy needs questionnaire and protocol for survivors of childhood cancer. J Paediatric Oncol Nurs. 2010.

[6] Hasseling P, Njume E, Kouya F, et al. The Cameroon 2008 Burkitt lymphoma protocol: improved event-free survival with treatment adapted to disease stage and the response to induction therapy. Paediatric Hematol Oncol. 2008; 29(2): 119-129. PMid:22376015 https://doi.org/10.3109/08880018.2011.644881

[7] Slone J, Chunda-Liyoka C, Perez M, et al. Paediatric malignancies, treatment outcomes and abandonment of Paediatric cancer treatment in Zambia. University Teaching Hospital/University of Zambia School of Medicine, Lusaka, Zambia; University of York, York, United Kingdom; Vanderbilt Institute for Global Health, Nashville. Sajjadi, Homeira Vameghi et al. Global Journal of health sciences. 2012.
[8] Bowman KF, Rose JH, Deimling GT. Appraisal of the cancer experience by family members and survivors in long-term survivorship. Journal of Psycho-Oncology. Social and Behavioural Dimensions of Cancer. 2006; 15(9): 834-845. https://doi.org/10.1002/pon. 1039

[9] Davis M, Lindsey L. A comparison of in-home and telephone-based skill training interventions with caregivers of persons with dementia. American Psychological Association. 2004; 10(1): 31-44.

[10] Glajchen M. Emerging role of caregivers in cancer care. Journal of Supportive Oncology. 2004; 2: 145-155. PMid:15328817

[11] Peterson A, Harper FWK, Fox J. Basic needs of Paediatric oncology patients, families, and their psychosocial adjustment. Journal of Clinical Oncology. 2013; 31(15): e20646.

[12] Yeh PM, Wierenga ME, Yuan SC. Influences of psychological wellbeing, quality of caregiver-patient relationship, and family support on the health of family aregivers for cancer patients in Taiwan. Asian Nursing Research. 2009; 3: 154-166. https://doi .org/10.101 6/S1976-1317 (09) 60027-X

[13] Cohen S, Janicki-Deverts D, Miller G. Psychological Stress and disease. The Journal of the American Medical Association. 2007; 298(14): 1685-1687. https://doi.org/10.1001/jama.298.1 4.1685

[14] Hannon B, Krzyzanowska M, Zimmermann C, et al. National Centre of biotechnology information, US national library of medicine. 8600 Rock view pk, Bethesda MD 20894 USA. 2004.

[15] Pascoe GC. Patient satisfaction in primary health care: a literature review and analysis. Evaluation and Program Planning. U.S.A. 1983; 
6: $185-210$.

[16] Marquis MS, Davies AR, Ware JE. Patient satisfaction and change in medical care provider: a longitudinal study. Med Care. 1983; 21: 821-829. https://doi.org/10.1097/00005650-1983080 00-00006

[17] Schubart J, Kinzie M, Farace E. Caring for the brain tumour patient: Family caregiver burden and unmet needs.USA. Neuro Onco. 2008; 10: 61-72. PMid:17993635 https ://doi .org/10.1215/152285 17-2007-040

[18] Sajjadi H, Vameghi M, Ghazinour M, et al. Caregivers' quality of life and quality of services for children with cancer: a review from Iran. 2013; 5(3): 173-82.

[19] Nagel K, Eves M, Waterhouse L, et al. The development of an offtherapy needs questionnaire and protocol for survivors of childhood cancer. Paediatric Oncol Nurs. 2002.

[20] Mack JW, Hildah JM. Parent and physician perspectives on quality of care at the end life in children with cancer. Clin Oncol. 2005; 23(36): 9155-9161. https://doi .org/10.1200/JC0.2005.04.010

[21] Ringdal G, Marit S. Journal of Pain Symptom Management. Norway. 2010.
[22] Joad A, Mayamol T, Chaturvedi M. What does the informal caregiver of a terminally ill Cancer patient Need? A study from a cancer centre. Indian J Palliat care. 2011 Sep- Dec; 17(3): 191-196.

[23] Weller B. Baillier's Nurses Dictionary. Elsevier; 2009.

[24] Iconomou G, Vagenakis AG, Kalofonos HP. The informational needs, satisfaction with communication, and psychological status of primary caregivers of cancer patients receiving chemotherapy. Support Care Cancer. 2001; 9(8): 591-6.

[25] McKenna K, Collier J, Hewitt M, et al. European Journal of Cancer Care. 2009; 19: 621-630.

[26] Lavergne MR, Johnston GM, Gao J, et al. Variation in the use of palliative radiotherapy at the end of Life: examining demographic, clinical, health service, and geographic factors in a population-based study. Pall Med. 2011; 25(2): 101-110. https://doi.org/10.1 $177 / 0269216310384900$

[27] Walker V, Jensen L, Oberie K. Nursing support for family members of critically ill adults. Lancet. 2007; 363; 2180-2185. https : //doi.org/10.1016/S0140-6736(04) 16511-2

[28] Chang J, Kwon Y, Lee W, et al. Burdens, needs and satisfaction of terminal cancer patients and their caregivers. National Cancer Control Institute and Hospital, National Cancer Center, Goyang, Korea. 2014. 